\title{
A fault-tolerant photovoltaic integrated shunt active power filter with a 27-level inverter
}

\author{
Kamel Saleh, Ameen Madi \\ Department of Electrical and Computer Engineering, An-Najah National University, Palestine
}

\begin{abstract}
Article Info
ABSTRACT

Article history:

Received Jul 26, 2020

Revised Sep 9, 2020

Accepted Oct 10, 2020

\section{Keywords:}

Fault-tolerant

Multilevel inverter

Shunt active power filter

Solar power generation

This paper introduces a fault-tolerant shunt active power filter (SAPF). The novility in of this work is that it poposes a solutions to increase the reliability of shunt active power filter to maintain its operation under a single-phase open-circuit fault in the SAPF. This will increase the reliability of the whole power system. The SAPF is composed of a 4-leg 27-level inverter based on asymmetric cascaded H-bridge topology. If an open-circuit fault is introduced to the operation of the SAPF, a special control technique will be implemented and the redundant leg of the SAPF will be activated. The faulttolerant SAPF can do many tasks under healthy operating conditions and post and open circuit fault depending on the state of charge (SOC) of the batteries. It can mitigate harmonics in the power system, improve power factor in the system by injecting reactive power, and inject real power to the system. The proposed SAPF is tested and simulated in MATLAB/Simulink and the results have shown a significant improvement in total harmonics distortion (THD) of the source current from $13.9 \%$ to $3.9 \%$ under the normal operating condition and from $42 \%$ to $8.4 \%$ post and open circuit fault.
\end{abstract}

This is an open access article under the CC BY-SA license.

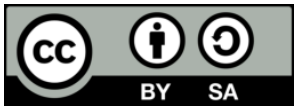

Corresponding Author:

Kamel Saleh

Department of Electrical Engineering

An-Najah National University

Nablus, West-Bank, Palestine

Email: kamel.saleh@najah.edu

\section{INTRODUCTION}

The nonlinear loads are wildly used in many fields of modern electrical systems such as electric vehicles, arc furnaces, and renewable energy sources [1-3]. These nonlinear loads increase the harmonic pollution in the main power system and consequently causing overheating and male functions in the power system components. To mitigate these harmonics, the passive filters were firstly introduced [4]. These passive filters were bulky, restricted to a limited range of harmonics, and causing resonance in the power system. Active power filters (APF) were introduced as a solution to the harmonic pollution problem. APF has many advantages over passive filters in terms of filtering accuracy, dynamic response, and scalability [5, 6]. However, the increased demand for power leads to an increase in the size, cost, and rating of these APFs $[7,8]$. The next development of power filters was the hybrid power filter (HPF) devices [9] while the newest active power filter that has recently been used is the unified power quality conditioner (UPQC) [10]. Several techniques were introduced in the literature to extract the harmonics contents from the current and voltage waveforms to mitigate them. The most used techniques are d-q, and p-q [11-14].

The multi-level inverter was presented in many papers as a replacement of the conventional 2-level and 3-level inverter [15]. Multi-level inverters are capable of generating almost sinusoidal output with low THD, less dv/dt, and higher outputs voltages. These features make multi-level inverter an ideal to be used in 
APFs [16]. The multi-level inverters can be classified into three classical topologies, namely, the neutral point clamped (or diode clamped) [17], the flying capacitor (or capacitor clamped) [18], and the cascaded multilevel converter [19]. Many research papers were published on new topologies of the multi-level inverters [20-22] and new modulation techniques for multi-level converters [23, 24].

Many research papers have outlined differnts topologies for a fault-tolerant inverter in literature. The use of the fault-tolerant inverter helps to increase te relaibilty of the electrical system by making use of the redundancy exists in these inverters [25]. This redundancy can be inherted in the structure of the inverter [26] or it is introduced intentinonally to the normal inverter to make it fault-tolerant [27]. Finally, post fault operation can be achieved in multi-level inverter using three scenarios including neutral-shift, DC-bus voltage reconfiguration, and redundant modules installation is employed [28, 29].

The paper is aiming to present a solution to maintain the operation of the SAPF in various conditions including a single-phase open-circuit fault in the SAPF to increase the reliability of the whole power system. The paper is presenting a fault-tolerant SAPF composed of a 4-leg 27-level inverter and battery storage. By using a special control technique under an open circuit fault, The SAPF can mitigate harmonic, inject real and reactive power under the healthy operating conditions and post an open-circuit fault without degradation of the system performance. This paper describes the topology of the system and shows simulation results with a small $15 \mathrm{KVA}$ prototype. The results emphasize the feasibility of the fault-tolerant active filters in decreasing significantly the THD under normal operating conditions, and post an-open circuit fault. Also, the paper shows the ability of such a filter to inject real power to support the grid in high-demand hours under the healthy operating conditions and post an open-circuit fault.

\section{RESEARCH METHOD}

\subsection{Fault-tolerant SAPF topology}

The topology of the 4-leg PV-SAPF system is shown in Figure 1. The SAPF is using a four-leg 27level asymmetrical cascaded H-Bridge inverter. Each leg has three H-bridges connected in series and supplied by three batteries. The batteries are fed form three photovoltaic arrays. Different combinations of photovoltaic arrays have been designed which can produce three values of dc power $(36 \mathrm{~V}, 108 \mathrm{~V}, 324 \mathrm{~V})$ and deliver $5 \mathrm{KVA}$ to each phase. P\&O maximum power point (MPPT) technique is used because to get maximum possible power from the solar energy [30].

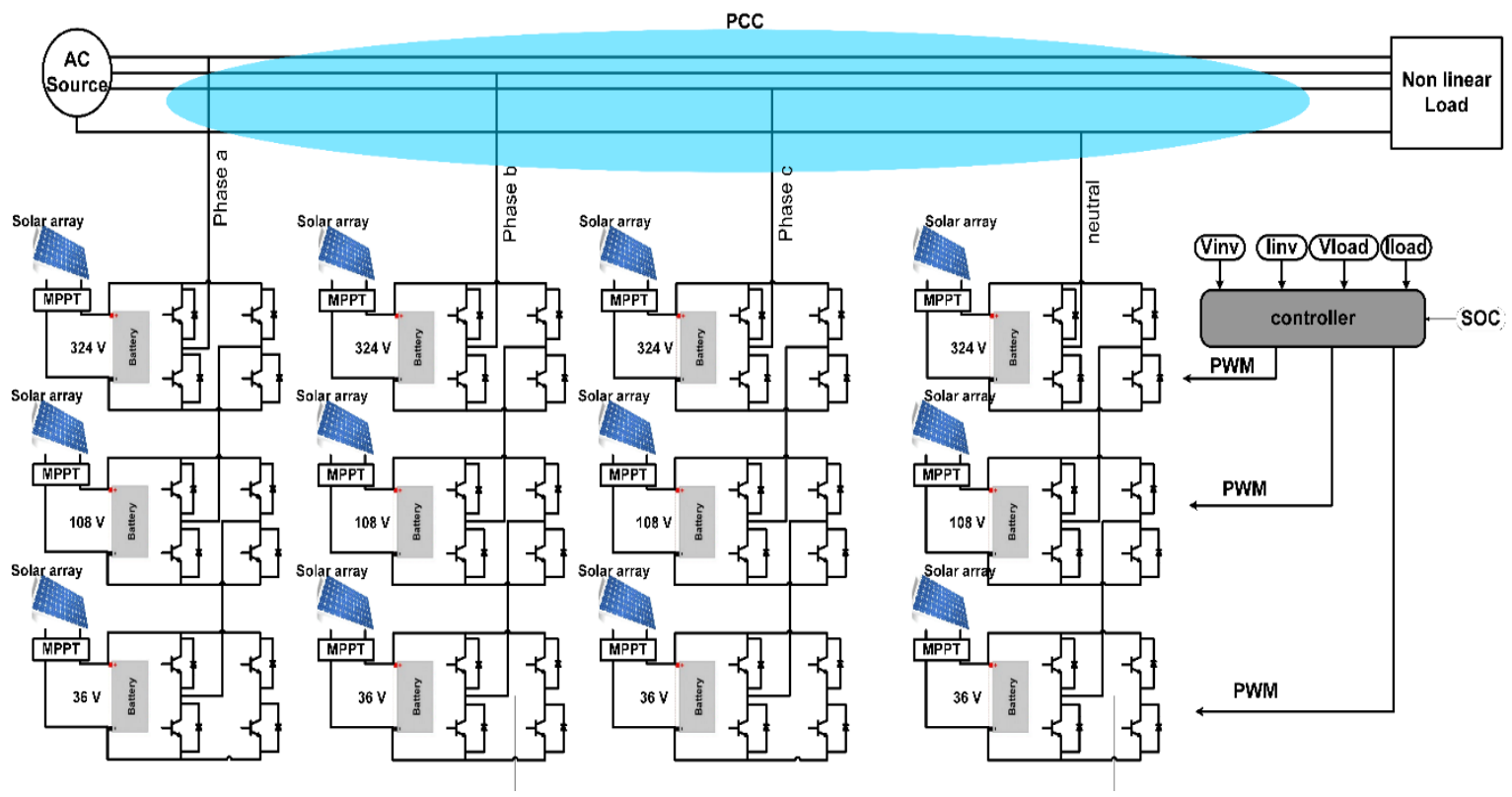

Figure 1. Power circuit structure of the PV-SAPF system

A $125 \mathrm{~W}$ polycrystalline PV modules (Mitsubishi Electric PV-EE125MF5F) have been used to design all photovoltaic arrays. These photovoltaic arrays are delivering $5 \mathrm{KVA}$ to each phase as shown in Table 1. A suitable three boost converters are used to fix regulate the output of the photovoltaic arrays to the 
values $(36 \mathrm{~V}, 108 \mathrm{~V}$, and $324 \mathrm{~V})$ in each leg. The maximum output voltage obtained in each leg of the $27-$ level inverter will be $468 \mathrm{~V}$.

The multi-level inverter that is used in this research is similar to one presented in [23]. One of the differences is that in this work three separate DC sources are used for each leg with the voltage equal to $36 \mathrm{~V}$, $108 \mathrm{~V}$ and $324 \mathrm{~V}$ that makes it possible to connect the SAPF to the PCC directly while in [23] a single DC source is used and three transformers with ratios $1: 1,1: 3$ and 1:9 are used to connect the SAPF to the PCC. Although this configuration reduces the number of the DC sources in each leg to 1 DC source, it is on the other hand using transformers which make the system less efficient. Moreover, The most important difference is that a fourth leg is added to the 27-level inverter in this research to increase the reliability of the SAPF and maintains its performance post and open circuit fault. The output of each H-Bridge and the output of one leg of the 27-level inverter are shown in Figure 2. The main H-Bridge is generating more than $80 \%$ of the total power and has a switching frequency of $50 \mathrm{~Hz}$ only which helps to reduce the switching losses and increases the efficiency of the multi-level inverter. The frequency of the auxiliary H-Bridges is also low but increases as the voltage level of the inverter become lower in the chain. Moreover, this 27-level inverter can generate a nearly sinusoidal output with THD is less than $1.8 \%$ making it an ideal solution in SAPFs.

Table 1. The combinations of PV module for designing photovoltaic arrays sources

\begin{tabular}{cccrrr}
\hline & Combination & Power(W) & Before boost converter & After boost converter & $(\%)$ \\
\hline AUX.1 & 1 in series*2 in parallel & 210 & 17 & 36 & $5 \%$ \\
AUX.2 & 3 in series*2 in parallel & 630 & 51 & 108 & $15 \%$ \\
MAIN & 9 in series*3 in parallel & 3360 & 221 & 324 & $80 \%$ \\
Total (w) & & & & $4.2 \mathrm{~kW}$ & \\
\hline
\end{tabular}

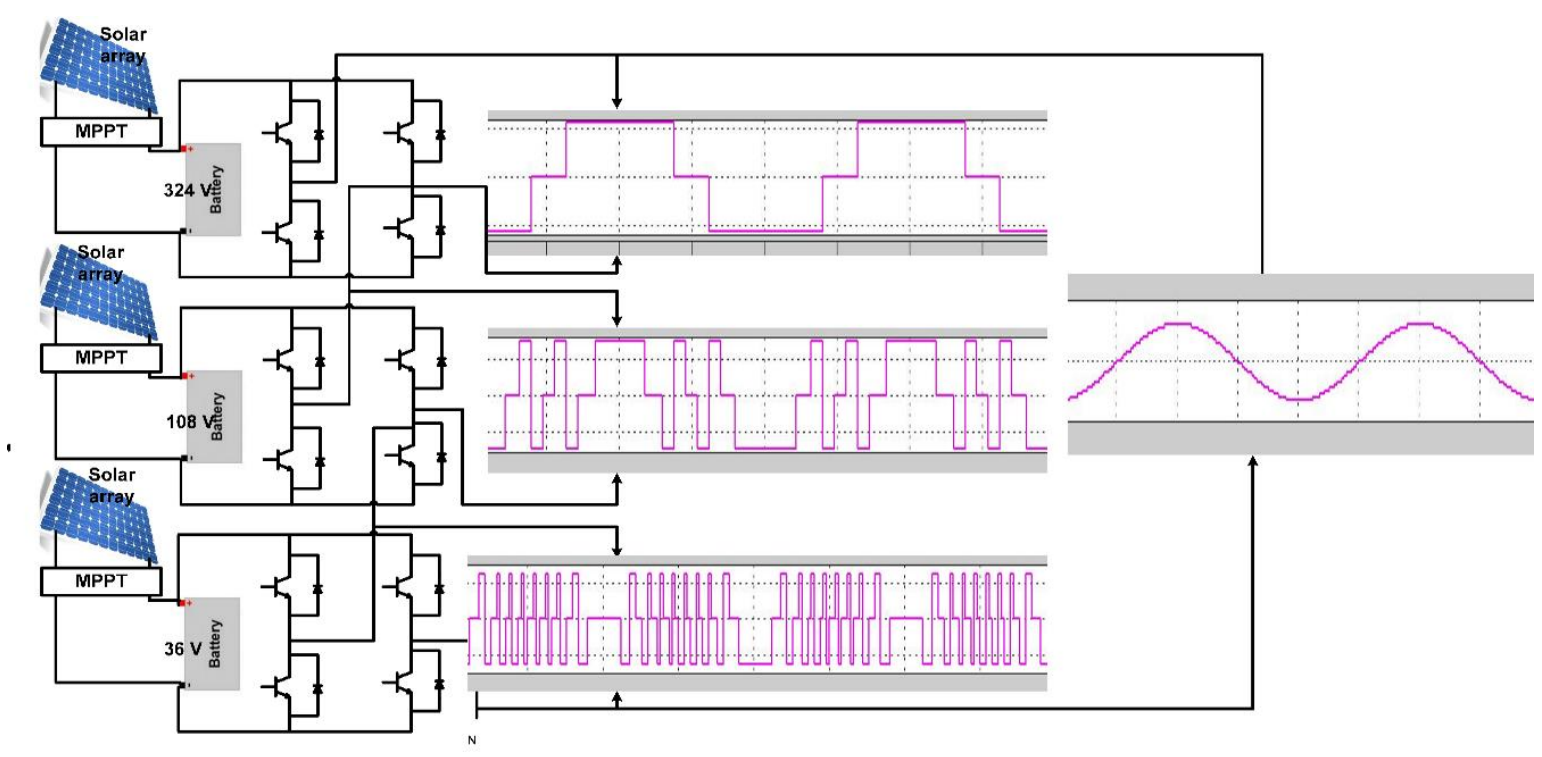

Figure 2. Asymmetric 27-level inverter

\subsection{Control Scheme under healthy operating condition}

The efficiency of the SAPF depends on the reference extraction method adopted. Many techniques are used to extract the reference signal. There are mainly two techniques, time-domain and frequency-domain [30]. In the time-domain, an instantaneous estimation is done to generate a reference signal from distorted load voltage or current. The time-domain method is simpler and needs less calculation compared to the frequency domain so the result will be faster [31].

\subsubsection{Instantaneous active and reactive current component (id-iq) method}

Synchronous reference d-q method was adopted in this research to calculate the current reference for the SAPF filter [11]. In this method, the instantaneous active and reactive current components of the nonlinear load are used to obtain the reference signal. This is done by mapping the nonlinear load current into load voltage (VL) rotating frame which is obtained using a phase-locked loop. In this case, the nonlinear load 
current will have two components idl in the direction of the load voltage and iql component perpendicular on the load voltage. Idl Represents the real power component while iql represents the reactive power component as shown in Figure 3. The formulas of these components are given below:

$$
\begin{aligned}
& \text { idl }=\widetilde{1 d}+\overline{l d} \\
& \text { iql }=\widetilde{l l q}+\overline{\mathrm{ll} q}
\end{aligned}
$$

where $\overline{\mathrm{ld}}, \overline{\mathrm{llq}}$ (DC components) represent the fundamental component of the non-linear load real and reactive power. While $\widetilde{\imath l d}$, $\widetilde{I l q}$ (the oscillating components) represents the harmonics in the non-linear load currents. The reference extraction method adopted in this project (id_ref and iq_ref) are illustrated in Figure 3. These reference signals id_ref and iq_ref will be generated according to the following actions:-

- $\quad$ Eliminate the $\widetilde{\imath l d} \& \widetilde{\mathrm{Ilq}}$ to eliminate harmonics in the load current.

- Eliminate $\overline{l l q}$ to improve the power factor.

- Eliminate $\overline{l l d}$ component can be changed to determine the amount of injected real power that the PV system can produce as shown in Figure 3.

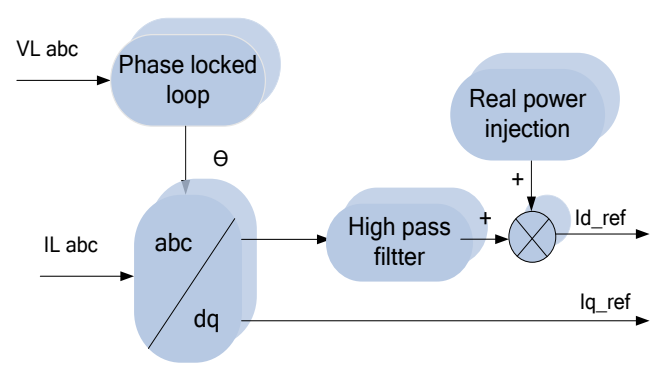

Figure 3. Principle of synchronous reference frame theory (d-q method)

Based on the above. The formula of id_ref and iq_ref are:

$$
\begin{aligned}
& i \mathrm{~d}_{\text {ref }}=\widetilde{\mathrm{ld}}+\mathrm{i}_{\text {inj }} \\
& \mathrm{iq}_{\mathrm{ref}}=\widetilde{\mathrm{Il}}+\overline{\mathrm{llq}}
\end{aligned}
$$

where $\boldsymbol{i}_{\boldsymbol{i n j}}$ represents the amount of real power injected by the active power filter.

\subsubsection{Modelling and control of shunt active filter}

Assuming that the SAPF is connected to the PCC through resistance and inductance as shown in Figure 4. The following equations hold true:

$$
\begin{aligned}
& v a_{i n v}=i a_{i n v} * r+L \frac{d i a_{i n v}}{d t}+v a_{p c c} \\
& v b_{i n v}=i b_{i n v} * r+L \frac{d i b_{i n v}}{d t}+v b_{p c c} \\
& v c_{i n v}=i c_{i n v} * r+L \frac{d i c_{i n v}}{d t}+v c_{p c c}
\end{aligned}
$$

The $(5,6,7)$ are transformed into the load voltage $d-q$ frame as follows:

$$
\begin{aligned}
& L \frac{d i d}{d t}=-i d * R+\left(V d_{i n v}-V d_{p c c}\right)-\omega * L * i q \\
& L \frac{d i q}{d t}=-i q * R+\left(V q_{i n v}-V a_{p c c}\right)+\omega * L * i d
\end{aligned}
$$

The (8) and (9) can be rewritten as: 


$$
\begin{aligned}
& v d=i d * R+L \frac{d i d}{d t} \\
& v q=i q * R+L \frac{d i q}{d t}
\end{aligned}
$$

Where

$$
\begin{aligned}
& v d=\left(V d_{i n v}-V d_{p c c}\right)-\omega * L * i q \\
& v q=\left(V q_{i n v}-V a_{p c c}\right)+\omega * L * i d
\end{aligned}
$$

A proportional-integral (PI) controller is used to control the d-q components of the inverter currents to equal the reference instantaneous real and reactive current components (ide_ref and iq_ref) given in (3) and (4) as shown in Figure 5. The outputs of the controllers (Vdq) are then used to generate pulses for the IGBTs in the multi-level inverter as shown in Figure 6.

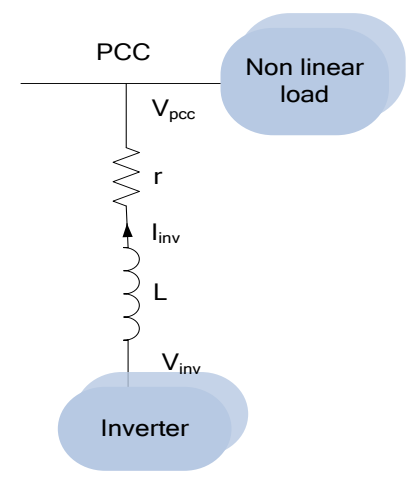

Figure 4. Dynamic modelling of the shunt active filter

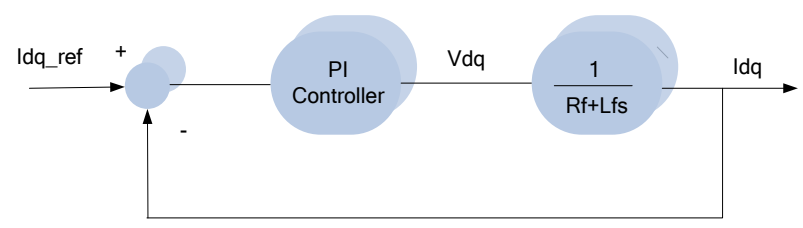

Figure 5. Closed loop control block diagram for shunt active filter under healthy operating condition

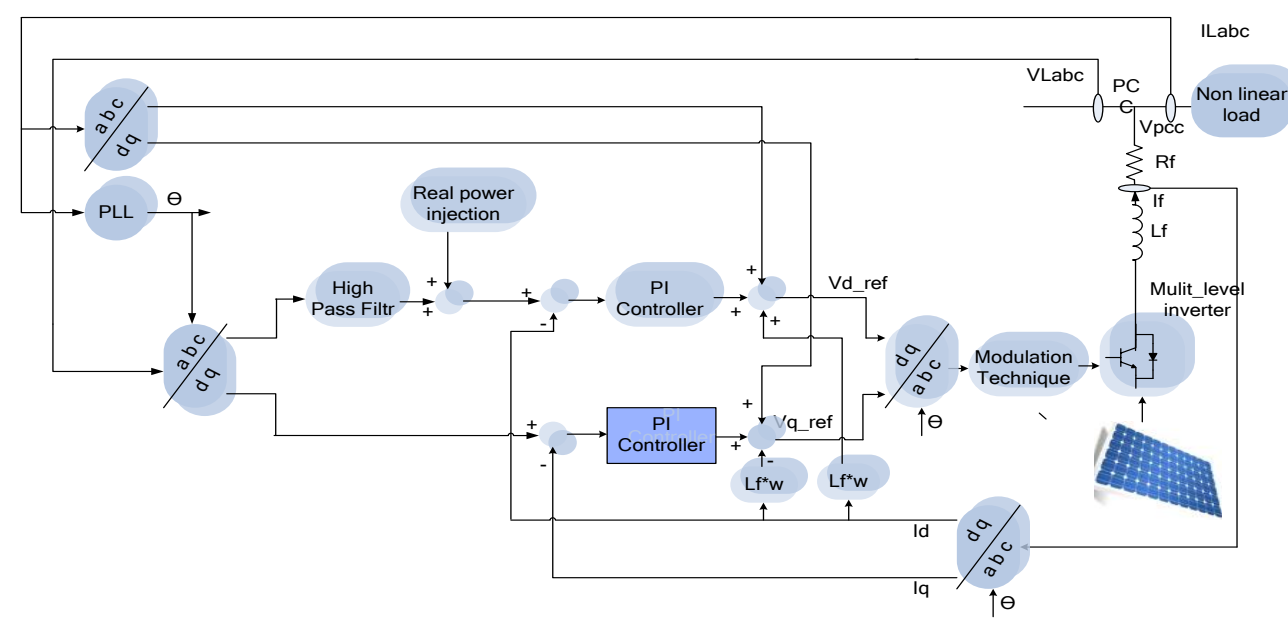

Figure 6 . The control structure of active filter under healthy operating condition 


\section{RESULTS AND DISCUSSIONS}

\subsection{Healthy operating condition}

The fault-tolerant SAPF is built and simulated in MATLAB/Simulink environment to check the performance and the correct working of the complete system under healthy operating condition. The simulation of the SAPF is tested to ensure the correct working of all system parts composed together.

\subsubsection{Harmonic elimination from source current}

Figure 7 shows the source current before and post the operation of the active filter. At $t=0.5 \mathrm{~s}$ the active power filter starts working to mitigate the harmonics in the source current according to the technique mentioned above. The results show how much improvement is achieved in the source currents. To illustrate the improvement in the source currents waveform, a fast Fourier transform (FFT) is applied to the source current before the active filter activation and post the use of the SAPF and the results are shown in Figure 8. The total harmonic distortion (THD) reduced from decreases from $13.9 \%$ to $3.9 \%$.

\subsubsection{Power factor correction}

The injection of reactive power $(\mathrm{Q})$ depends on the tuning of iq-ref current, where iq-ref set to maintain a unity power factor by injecting reactive power. Figure 8 shows the effectiveness of the shunt active power filter (SAPF) in improving the power factor at the source current to be near unity. At $t=0.4 \mathrm{~s}$, the shunt active filter starts to inject reactive power and the power factor has been improved from 0.78 to 0.97 .

\subsubsection{Real power injection}

The SAPF can be controlled to inject the real power by adjusting the value of id-ref current. The amount of real power injected depends on the SOC of all battery packs. Figure 9 shows the change in source current when the system starts active power injection at $\mathrm{t}=1 \mathrm{~s}$. The injection of real power has been stopped at $\mathrm{t}=1.5 \mathrm{~s}$ and the source current returns to its previous value before the real power injection.
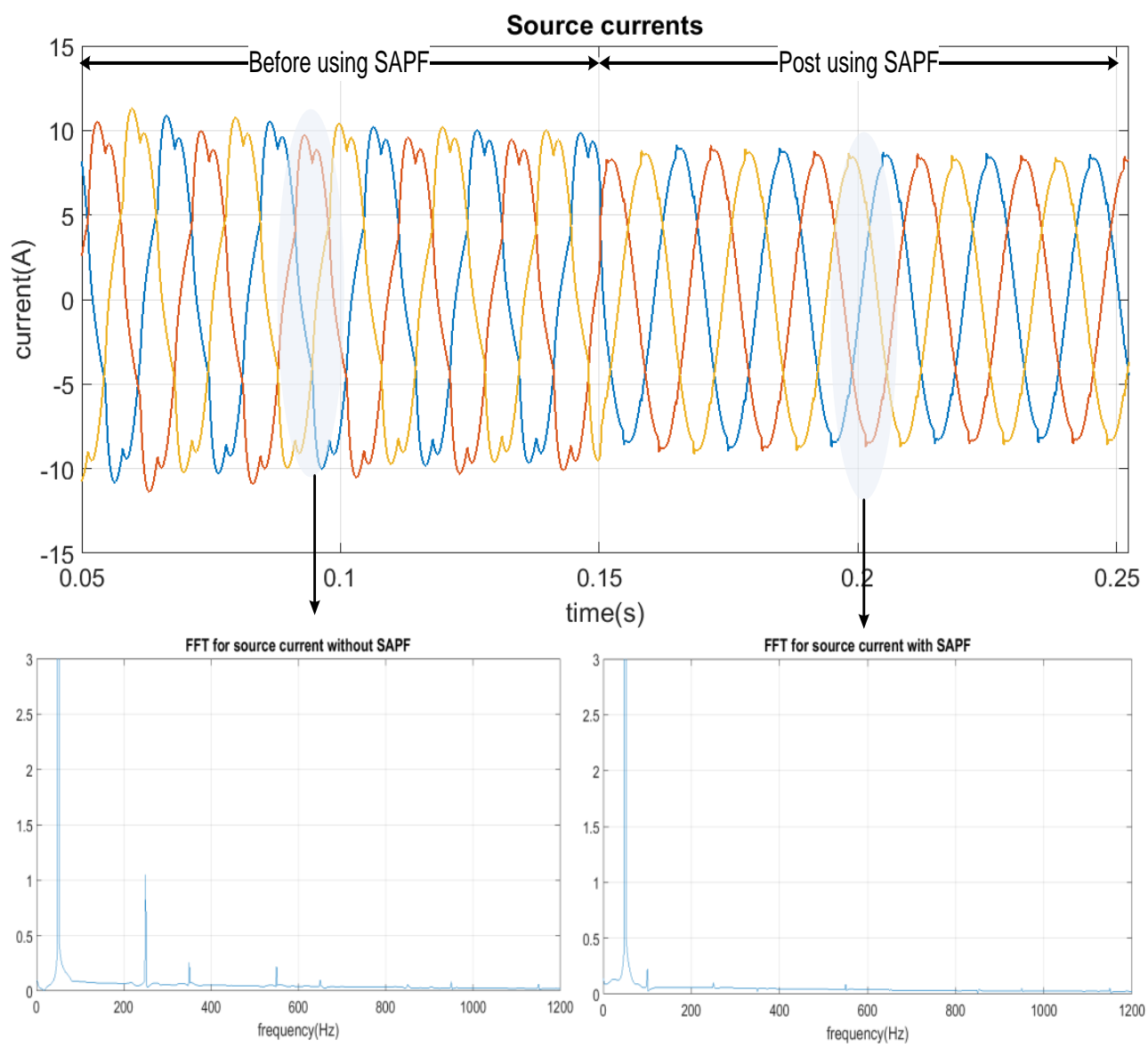

Figure 7. Source current waveforms before and post the operation of active filter 

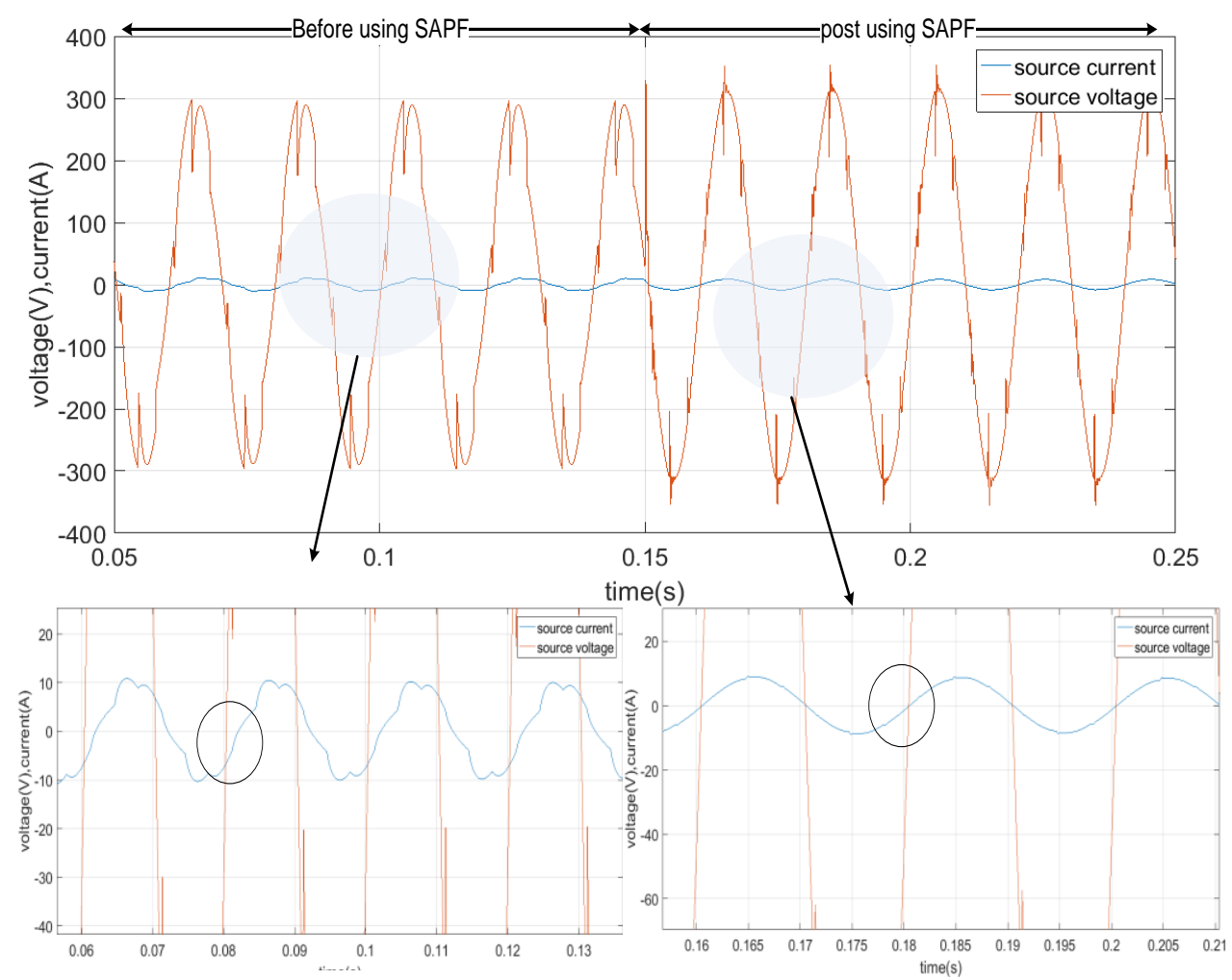

Figure 8. Source current waveform after reactive power injection using active filter under

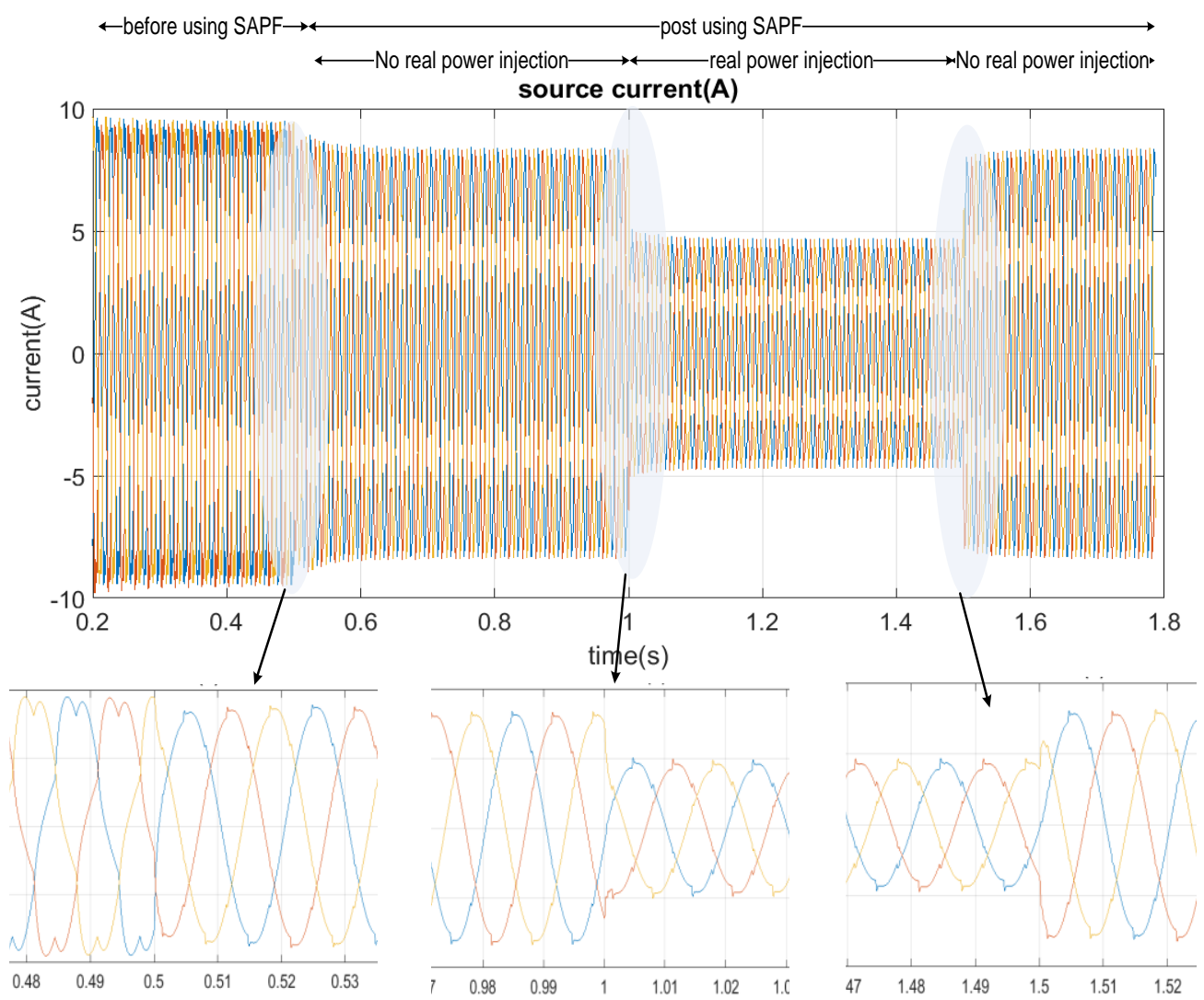

Figure 9. Source current waveforms after real power injection 


\subsection{Control of SAPF post an open circuit fault}

Although of its advantages, the multi-level inverter can be affected by abnormal conditions which can damage the power switches causing faults in the system. Three main types of failure of power switches operation can occur such as the intermittent gate-misfiring fault, open circuit fault, and the short-circuit fault. So, to achieve the reliability and availability of the inverters, some fault-tolerance techniques have to be applied to ensure that the inverter still can operate under fault conditions.

In this paper, an open circuit fault for one phase of the inverter is considered by assuming one leg is disconnected (phase 'c') as shown in Figure 10. The effect of an open-circuit fault on the performance of the SPAF without applying any fault-tolerant control technique is shown in Figure 10. The IGBTs in the fourth leg is still disabled.

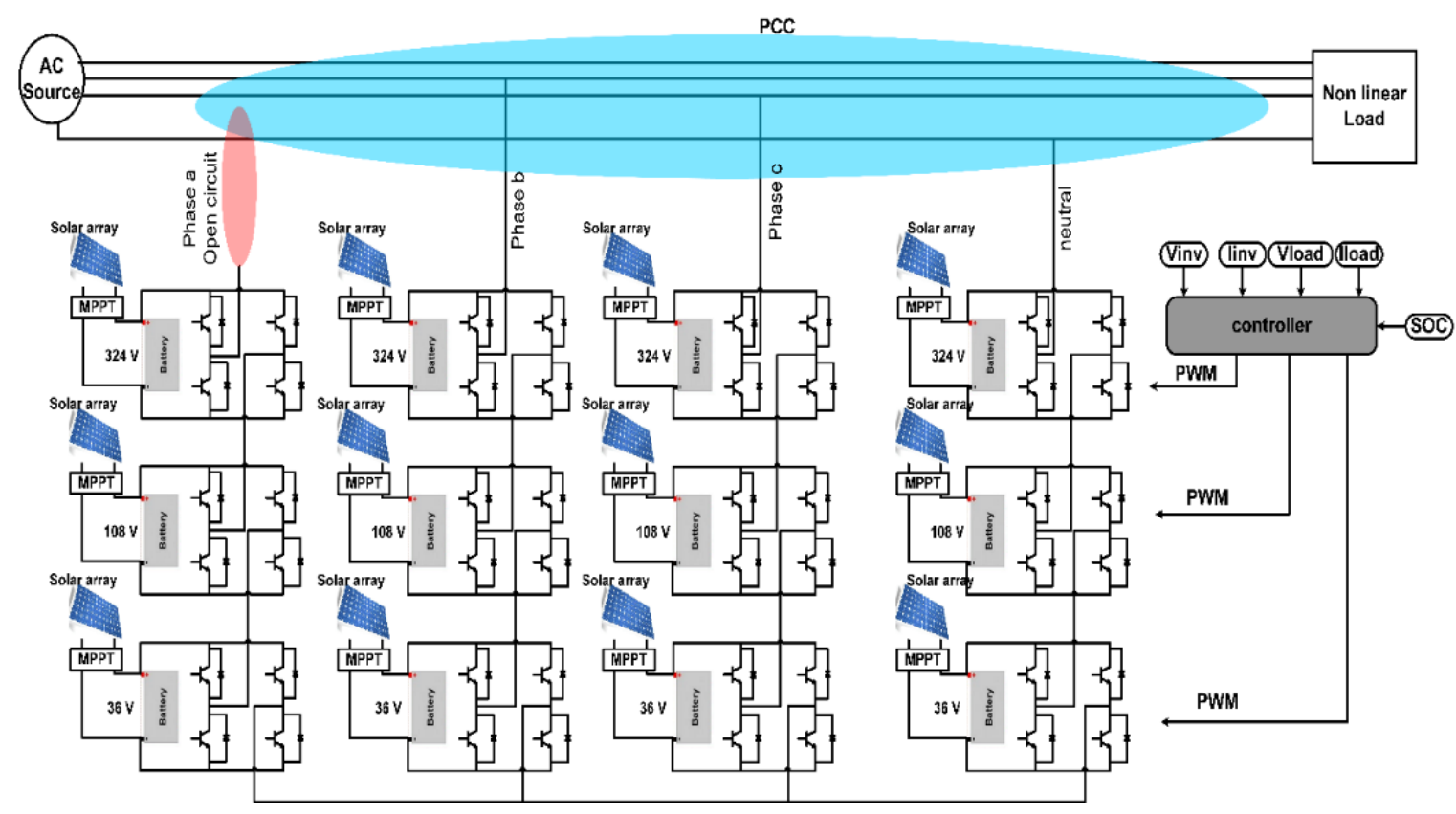

Figure 10. Power circuit structure of the PV-SAPF system post an open-circuit fault

Figure 11 shows that the harmonic content in the source currents post the fault has been increased significantly and the source currents became much distorted. The THD in the source current is increased from $13.9 \%$ to $40 \%$ post an open circuit fault. This results can be understood from the fact the SAPF start to inject harmonics at PCC post the fault instead of mitigating them due to the fact that the control technique that is applied under healthy operating condition is no longer applicable post the open-circuit fault. And hence a new fault-tolerant control technique should be applied.

The control strategy adopted in this research post an open-circuit fault is consisting of two sides which are hardware and software. The hardware side is based on adding a redundant fourth leg to the inverter which will be connected to the neutral of the load as shown in Figure 11. The added fourth leg helps to provide the ability for the inverter to tolerate an open phase fault. This leg is disconnected during healthy operating conditions through deactivating the IGBTs switches in that leg. When an open-circuit fault is introduced to one leg of the multi-level inverter, the faulted leg will be disconnected through deactivating the IGBTs switches in the faulted leg and the IGBTs in the fourth leg will be activated to control the voltage at the neutral point. The software side is based on modifying the control strategy to control the remaining two healthy phases of the multi-level inverter according to the following steps:

- The reference voltage of the faulty phase is set to zero, for example, if phase c becomes faulty then Vc_ref and Ic_inv should be zero.

- Activating the switches which connect the fourth leg of the inverter to the neutral point of the load.

- Controlling the zero sequence currents.

The adopted fault-tolerant control technique is illustrated in Figure 12. The blocks and wires in red refer to the parts of the control technique that are modified to make it a fault-tolerant technique according to the steps mentioned above. The fault-tolerant technique shown in Figure 12 is implemented in the MATLAB/Simulink environment. And the results of the source currents (abc), multi-level inverter currents 
(abc), and multi-level inverter currents (dq0) are shown in Figure 13. Before $t=0.5 \mathrm{~s}$, the SAPF was disabled (i.e no SAPF), this can be proved from the multi-level inverter currents (abc) which were equals to zero. At $\mathrm{t}=0.5 \mathrm{~s}$, The SAPF started to mitigate the harmonics and inject reactive power under healthy operating condition. This can be noticed from the source currents waveforms as they became undistorted. Also, it can be noticed that the multi-level inverter currents became non zero. Then at time $t=1 \mathrm{~s}$, phase ' $a$ ' open circuit fault was introduced to the operation of the SAPF without applying any fault-tolerant control technique and without enabling the fourth leg of the multi-level inverter. This can be seen from the multi-level inverter currents. The source currents, in this case, were very distorted. At $t=1.5 \mathrm{~s}$, the fourth leg of the multi-level inverter was activated and the fault-tolerant technique is implemented. The source currents waveform, in this case, were returned to be the same as that measured pre the fault condition. Finally, at $\mathrm{t}=2 \mathrm{~s}$, the SAPF started to inject real power under phase 'a' open circuit condition. The magnitude of the source currents was reduced. These results demonstrated the effectiveness of using the fault-tolerant technique for mitigation the harmonics, inject real and reactive power under an open circuit fault condition.

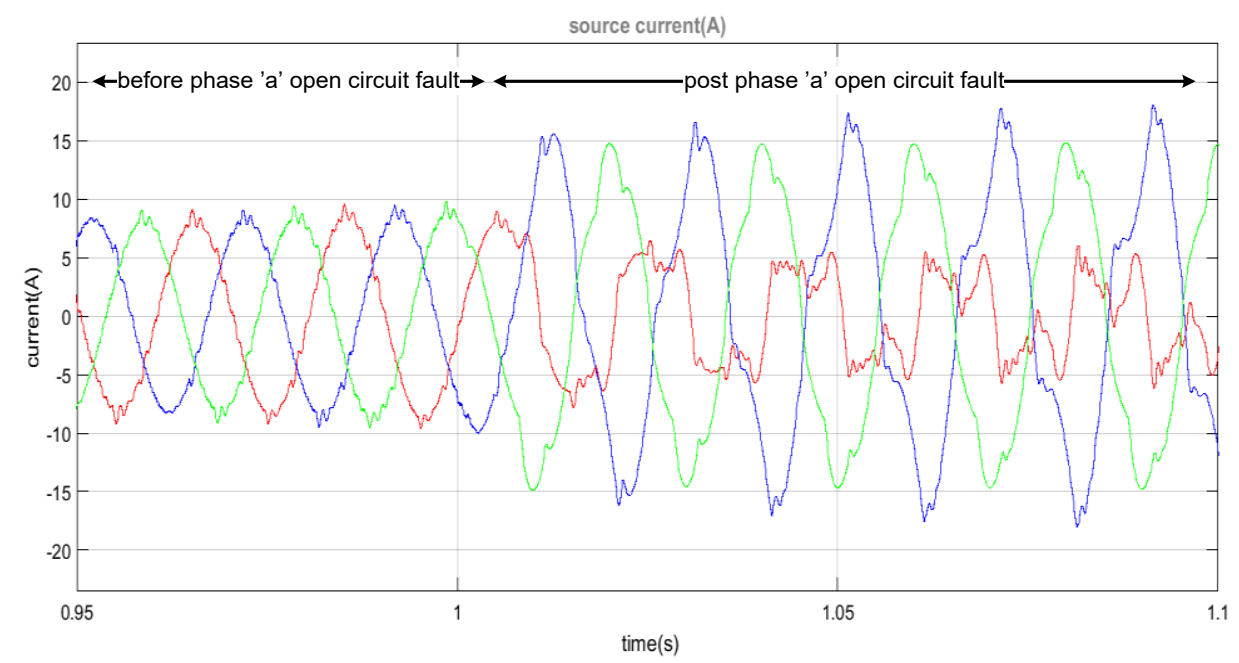

Figure 11. source currents waveforms post an open-circuit fault without modifying control strategy

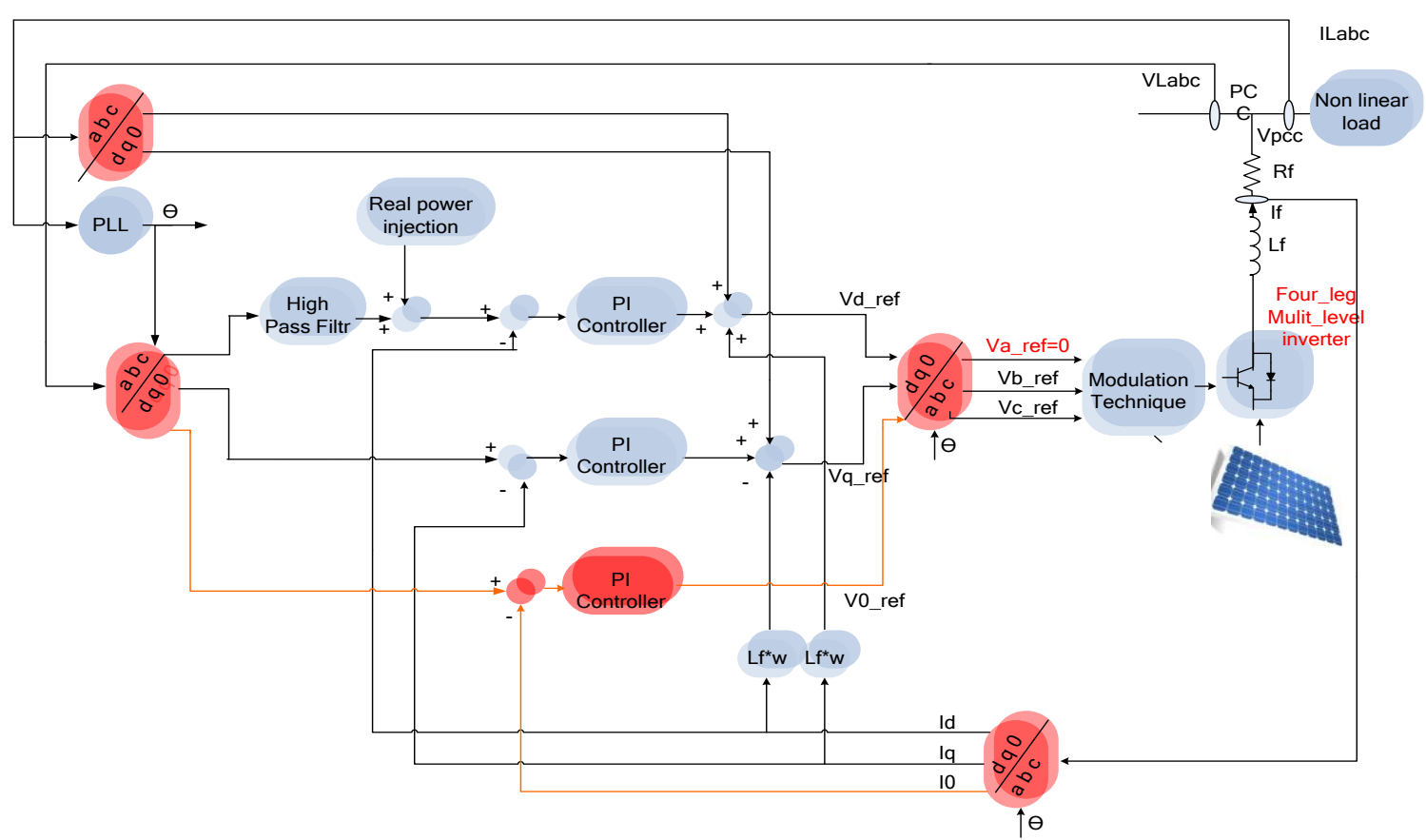

Figure 12. Control strategy scheme to tolerate an open circuit fault 

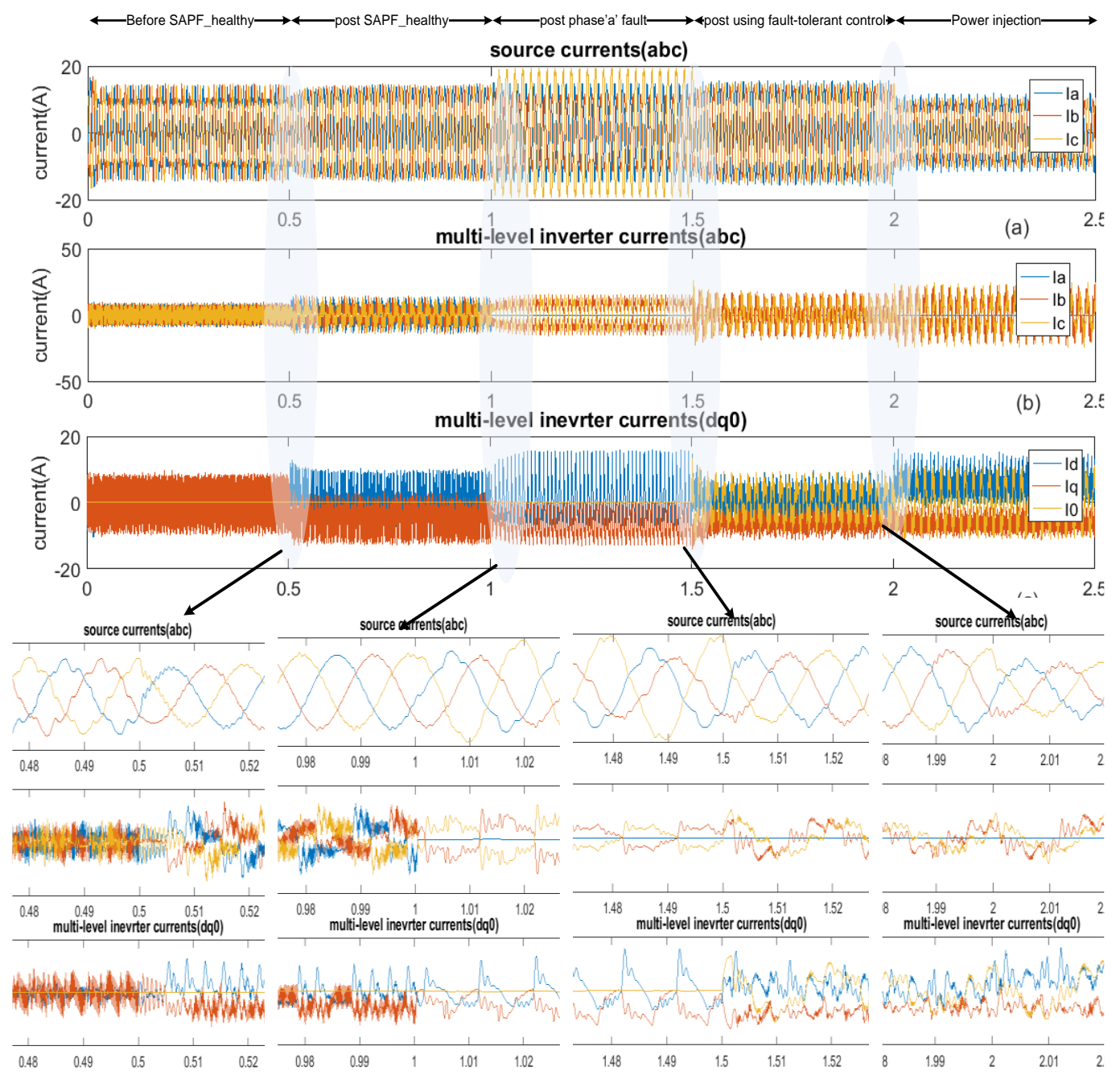

Figure 13. Source currents after under an open-circuit fault condition before and post applying the faulttolerant control technique

\section{CONCLUSION}

This paper has presented a solution to maintain the operation of the SAPF in case of a single-phase open-circuit fault by using a fault-tolerant multi-level inverter controlled through a special control technique. This has increased the reliability of the whole power system. The fault-tolerant shunt active power filter (SAPF) can do many tasks under healthy operating conditions and post and open circuit fault. It can mitigate harmonics in the power system, improve power factor in the system by injecting reactive power, and inject real power to the system. The proposed SAPF is tested and simulated in MATLAB/Simulink and the results have shown a significant improvement in total harmonics distortion (THD) of the source current form $13.9 \%$ to $3.9 \%$ under the normal operating conditions and from $42 \%$ to $8.4 \%$ post and open circuit fault.

\section{REFERENCES}

[1] K. Lee, D. Carnovale, D. Young, D. Ouellette and J. Zhou, "System harmonic interaction between DC and AC adjustable speed drives and cost effective mitigation," 2015 IEEE Energy Conversion Congress and Exposition (ECCE), Montreal, QC, 2015, pp. 4069-4076.

[2] E. Hoene, G. Deboy, C. R. Sullivan and G. Hurley, "Outlook on Developments in Power Devices and Integration: Recent Investigations and Future Requirements," in IEEE Power Electronics Magazine, vol. 5, no. 1, pp. 28-36, 2018.

[3] IEEE Standards Association, "IEEE Recommended Practices and Requirements for Harmonic Control in Electrical Power Systems," in IEEE Std. 519-1992, pp. 1-112, Apr. 1993.

[4] F. Z. Peng, H. Akagi and A. Nabae, "A new approach to harmonic compensation in power systems-a combined system of shunt passive and series active filters," in IEEE Transactions on Industry Applications, vol. 26, no. 6, pp. 983-990, 1990. 
[5] J. A. Palmer, R. C. Degeneff, T. M. McKernan and T. M. Halleran, "Pipe-type cable ampacities in the presence of harmonics," in IEEE Transactions on Power Delivery, vol. 8, no. 4, pp. 1689-1695, 1993.

[6] J. Faiz, M. Ghazizadeh and H. Oraee, "Derating of transformers under non-linear load current and non-sinusoidal voltage-an overview," in IET Electric Power Applications, vol. 9, no. 7, pp. 486-495, 2015.

[7] C. Lam, W. Choi, M. Wong and Y. Han, "Adaptive DC-Link Voltage-Controlled Hybrid Active Power Filters for Reactive Power Compensation," in IEEE Transactions on Power Electronics, vol. 27, no. 4, pp. 1758-1772, 2012.

[8] J. Espi, R. Garcia-Gil, J. Castello, "Capacitive Emulation for LCL-Filtered Grid-Connected Converters," in Energies, vol. 10, no. 7, p. 930, 2017.

[9] S. P. Litrán and P. Salmerón, "Analysis and design of different control strategies of hybrid active power filter based on the state model," in IET Power Electronics, vol. 5, no. 8, pp. 1341-1350, 2012.

[10] O. Prakash Mahela and A. Gafoor Shaik, "A Topological aspects of power quality improvement techniques: A comprehensive overview," Renewable and Sustainable Energy Reviews, vol. 58, pp. 1129-1142, 2016.

[11] H. Akagi, Y. Kanazawa, A. Nabae, "Generalized Theory of the Instantaneous Reactive Power in Three-Phase Circuits," Electrical Engineering in Japan, vol. 103, no. 4, pp. 483-490, 1983.

[12] M. Depenbrock, "The FBD-method, a generally applicable tool for analyzing power relations," in IEEE Transactions on Power Systems, vol. 8, no. 2, pp. 381-387, 1993.

[13] L. S. Czarnecki, "Orthogonal decomposition of the currents in a 3-phase nonlinear asymmetrical circuit with a nonsinusoidal voltage source," in IEEE Transactions on Instrumentation and Measurement, vol. 37, no. 1, pp. 30-34, 1988.

[14] S. Bhattacharya and D. Divan, "Synchronous frame based controller implementation for a hybrid series active filter system," IAS '95. Conference Record of the 1995 IEEE Industry Applications Conference Thirtieth IAS Annual Meeting, Orlando, FL, USA, vol. 3, pp. 2531-2540, 1995.

[15] Jih-Sheng Lai and Fang Zheng Peng, "Multilevel converters-a new breed of power converters," in IEEE Transactions on Industry Applications, vol. 32, no. 3, pp. 509-517, 1996.

[16] J. Rodriguez, Jih-Sheng Lai and Fang Zheng Peng, "Multilevel inverters: a survey of topologies, controls, and applications," in IEEE Transactions on Industrial Electronics, vol. 49, no. 4, pp. 724-738, 2002.

[17] Nabae, I. Takahashi and H. Akagi, "A New Neutral-Point-Clamped PWM Inverter," in IEEE Transactions on Industry Applications, vol. IA-17, no. 5, pp. 518-523, 1981.

[18] C. Hochgraf, R. Lasseter, D. Divan and T. A. Lipo, "Comparison of multilevel inverters for static VAr compensation," Proceedings of 1994 IEEE Industry Applications Society Annual Meeting, Denver, CO, USA, vol. 2, pp. 921-928, 1994.

[19] R. Teodorescu, F. Blaabjerg, J. K. Pedersen, E. Cengelci and P. N. Enjeti, "Multilevel inverter by cascading industrial VSI," in IEEE Transactions on Industrial Electronics, vol. 49, no. 4, pp. 832-838, 2002.

[20] Hasan, Md M., Abu-Siada, A., Islam, Syed M., Muyeen, S. M., "A Novel Concept for Three-Phase cascaded Multilevel Inverter Topologies," Energies, vol. 11, no. 2, p. 268, 2018.

[21] K. B. M. Reddy and S. Pattnaik, "Novel symmetric and asymmetric topology of multilevel inverter with reduced number of switches," 2017 International Conference on Trends in Electronics and Informatics (ICEI), Tirunelveli, 2017 , pp. 255-260.

[22] Martinez-Rodrigo, Fernando, Ramirez, Dionisio, Rey-Boue, Alexis B., De Pablo, Santiago, Herrero-de Lucas, and Luis C., "Modular Multilevel Converters: Control and Applications," Energies, vol. 10, no. 11, p. 1709, 2017.

[23] Moranchel, Miguel, Huerta, Francisco, Sanz, Inés, Bueno, Emilio, Rodríguez, Francisco J., "A Comparison of Modulation Techniques for Modular Multilevel Converters," Energies, vol. 9, no. 12, p. 1091, 2016.

[24] P. Flores, J. Dixon, M. Ortuzar, R. Carmi, P. Barriuso and L. Moran, "Static Var Compensator and Active Power Filter With Power Injection Capability, Using 27-Level Inverters and Photovoltaic Cells," in IEEE Transactions on Industrial Electronics, vol. 56, no. 1, pp. 130-138, 2009.

[25] W. Zhang, D. Xu, P. N. Enjeti, H. Li, J. T. Hawke and H. S. Krishnamoorthy, "Survey on Fault-Tolerant Techniques for Power Electronic Converters," in IEEE Transactions on Power Electronics, vol. 29, no. 12, pp. 6319-6331, 2014.

[26] M. A. Rodriguez, A. Claudio, D. Theilliol, L. G. Vela and L. Hernandez, "A strategy to replace the damaged element for fault-tolerant induction motor drive," 2008 5th International Conference on Electrical Engineering, Computing Science and Automatic Control, Mexico City, 2008, pp. 51-55.

[27] Jen-Ren Fu and T. A. Lipo, "Disturbance-free operation of a multiphase current-regulated motor drive with an opened phase," in IEEE Transactions on Industry Applications, vol. 30, no. 5, pp. 1267-1274, 1994.

[28] Mohammadpour, S. Sadeghi and L. Parsa, "A Generalized Fault-Tolerant Control Strategy for Five-Phase PM Motor Drives Considering Star, Pentagon, and Pentacle Connections of Stator Windings," in IEEE Transactions on Industrial Electronics, vol. 61, no. 1, pp. 63-75, 2014.

[29] P. Lezana, J. Pou, T. A. Meynard, J. Rodriguez, S. Ceballos and F. Richardeau, "Survey on Fault Operation on Multilevel Inverters," in IEEE Transactions on Industrial Electronics, vol. 57, no. 7, pp. 2207-2218, 2010.

[30] K. Gupta and R. Saxena, "Review on widely-used MPPT techniques for PV applications," 2016 International Conference on Innovation and Challenges in Cyber Security (ICICCS-INBUSH), Noida, pp. 270-273, 2016.

[31] S. Chandrasekaran and K. Ragavan, "Sliding DFT assisted instantaneous symmetrical components method for estimating reference current to Active Power Filter," 2012 IEEE 55th International Midwest Symposium on Circuits and Systems (MWSCAS), Boise, ID, 2012, pp. 1168-1171. 


\section{BIOGRAPHIES OF AUTHORS}

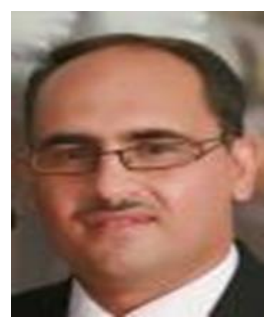

Kamel Saleh (Non-member) was born in Tulkarm, Palestine, in 1980. He received the B.E. degree in electrical engineering from An-Najah National University in 2003. From 2003 to 2005, he worked as a planning engineer with the Palestinian Energy Authority. In 2005, He joined Nottingham University as a graduate student and obtained a master degree and $\mathrm{PhD}$ degree in electrical engineering in 2006 and 2009 respectively. From 2009 to 2010, he worked as a researcher with as a power electronics, control, and machine (PEMC) group at Nottingham university. Finally, in 2010 he joined the department of electrical engineering at An-Najah National university as a lecturer. Finally, in 2018 he was promoted to be associated professor. His current researches include sensorless control of multi-phase drive, Multilevel inverters drives, DSTATCOM and renewable energy.

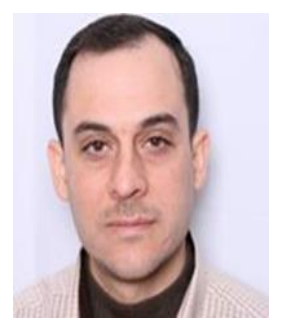

Ameen Madi (Non-member) was born in Tulkarm, Palestine. He received the B.E. degree in electrical engineering from Birzeit University in 2005. He received Mater degree in Electrical Engineering form An-Najah National University in 2018. Currently he is working at Al qudsopen unibersity. 